\title{
AC 2008-270: THE EFFECT OF A TARGETED SPEECH COMMUNICATION COURSE ON THE PUBLIC SPEAKING SELF-EFFICACY OF ENGINEERING UNDERGRADUATES
}

\section{Mieke Schuurman, Pennsylvania State University}

Mieke Schuurman is an engineering education research associate with the Leonhard Center for the Enhancement of Engineering Education in the College of Engineering at The Pennsylvania State University. She received her Masters and $\mathrm{PhD}$ in Social \& Organizational Psychology from the University of Groningen (The Netherlands). Her work focuses on the enhancement of engineering education. She is a member of ASEE and WEPAN, and actively involved in ASEE's Cooperative Education Division as their Research Chair. She has presented her work at annual conferences of ASEE, WEPAN, and CEIA, and published in the Journal of Engineering Education, the Journal of Language and Social Psychology, the Journal of Applied Social Psychology, the European Journal of Social Psychology, and the European Review of Social Psychology.

\section{Michael Alley, Pennsylvania State University}

Michael Alley is an associate professor of engineering communication in the College of Engineering at The Pennsylvania State University. He is the author of The Craft of Scientific Presentations (Springer, 2003) and regularly gives workshops on engineering presentations for different institutions including Sandia National Laboratories, the SPIE, Los Alamos National Laboratory, and Simula Research Laboratory (Norway).

Melissa Marshall, Pennsylvania State University

Melissa Marshall is a lecturer with the Department of Communication Arts and Sciences in the College of the Liberal Arts at The Pennsylvania State University.

\section{Christopher Johnstone, Pennsylvania State University}

Christopher Johnstone is an associate professor of Communication Arts and Sciences with the College of the Liberal Arts at The Pennsylvania State University. 


\title{
The Effect of a Targeted Speech Communication Course on the Public Speaking Self-Efficacy of Engineering Undergraduates
}

\begin{abstract}
This paper reports on how tailoring a speech communication course at The Pennsylvania State University specifically for engineering undergraduates affected the public speaking selfefficacy of those students - a project partially funded by the Engineering Information Foundation. This paper focuses on the following research question: Did engineering students who completed an engineering section feel more confident in their ability to communicate effectively than engineering students who completed a regular section?

Overall, students in the engineering sections increased their public speaking self-efficacy slightly more than students in the regular sections; this difference approached statistical significance $(p=.06)$. One reason the differences in the increases were not statistically significant might have been because of the relatively small sample sizes: 52 reporting in the engineering sections, but only 23 engineering students reporting from the regular sections. One statistically significant increase did occur for the issue of visual aids (.02), which is not surprising since the engineering sections taught the assertion-evidence slide design, which has a stronger theoretical basis than the commonly followed topic-subtopic design propagated by PowerPoint's defaults. Approaching statistical significance was the issue of delivery, which follows because the engineering sections promoted the engineering style of thinking through the content and maintaining eye contact while speaking, as opposed to continually looking down at note cards. Because of these increases in the scores and the enthusiasm shown by the participating students for the engineering sections, the College of Engineering desires to increase the number of engineering sections to meet the anticipated demand.
\end{abstract}

\section{Introduction}

A challenge for engineering colleges, particularly large colleges, is to improve the presentation skills of students. One common strategy is to have engineering students take a general speech course from a communications department. Another strategy is to incorporate speaking components into engineering courses such as senior design. Still a third strategy, which The Pennsylvania State University has adopted, is to use a combination of these two strategies.

In theory, a combination of the general speech course with the discipline-specific presentation components should provide students with a balance between general communication theory and practical advice. In practice, though, we have observed that students perceive conflicts in the advice that they receive from the speech course and the engineering courses with presentation components. For instance, some students point out that speaking from note cards is allowed (and even encouraged) in the general speech courses, but is frowned upon in the engineering courses on the grounds that, for engineering audiences, holding onto note cards undercuts the credibility of the speaker. 
Another problem is that engineering students often do not appreciate communication principles, such as rhetorical analysis, in the general speech course because they often do not see the connections between these principles and their own discipline. Because so many disciplines are represented in this course, the instructor understandably relies on general terms, examples, and assignments. For instance, the phrase "give a speech," which is used throughout the course, is not a phrase used in engineering - rather, "give a presentation" is the common term. While the difference between the two phrases does not bother an expert in the discipline of engineering, the difference might be confusing to a novice. Although many engineering students do not feel the content of the general speech course applies to them, the truth is that the content-listening critically, audience analysis, and the classical canons of rhetoric - actually has deep connections with engineering [1]. However, the engineering student needs to see those connections.

That many of the students do not make connections between the principles of the general speech course and the presentations they make in engineering was made apparent in a study at our institution. This study surveyed co-op supervisors on the presentation skills of our institution's students. The study revealed that the differences in the presentation skills of engineering students who took this general education course and engineering students who did not were not statistically significant. In other words, the students who passed through the course did not appear to apply what they had learned.

Given these problems, the question arises whether the content of the general speaking course could simply be replaced by the presentation-components of the engineering courses. Certainly, having engineering students make presentations in engineering courses and receive instruction and feedback from engineering faculty is valuable. In fact, we assert that the best education of engineering undergraduates in oral communication involves the students taking both a speech communication course and a series of engineering courses with presentation components.

However, a review of the literature does not support simply replacing a speech course taught by communication specialists with presentation components in engineering courses. If the presentation-component courses in engineering have the sole responsibility of educating the students about oral communication principles, then engineering faculty will be called upon to teach communication issues such as nonverbal signals for which they certainly have practical experience, but little theoretical understanding. That situation invites identification of simple rules that do not apply outside of certain situations and that do not make the students critical thinkers about oral communication. For instance, almost all of the reported instruction given to students in one documented presentation-component course [2] falls in the category of common sense: "speak clearly and loud enough to be heard," "look at the audience and not the script or projection screen," and "make visual aids clear and easy to read." In another documented presentation-component course [3], the engineering professor went so far as to assert that "a discussion of the principles of good oral communication contains no more than eight or ten items that, once you hear them, are intuitive and obvious." Oral communication principles have much more depth than this assessment. For instance, the issue of slide design is complex - balancing the goals of communicating content [4] and supporting arguments [5], but avoiding the common pitfall of cognitive overload [6] as occurs so often in slide designs that follow PowerPoint's defaults [7].

Our paper presents the assessment of a special section of a general speech course that targets engineering majors. This engineering section, taught by an instructor from 
Communications Arts and Sciences who receives consulting from an engineering faculty member, has three main goals. The first is to fulfill the general education requirements of the parent course. The second is to apply the principles of the course to engineering examples, so that students can appreciate the importance of those principles. The third goal is to make students aware of the nuances of engineering presentations, so that they are prepared for the speaking situations they will encounter in upper-level courses and in the profession. The content and instructional strategies of the course have been arrived at through continuing consultations between faculty in the Department of Communications Arts and Sciences and the College of Engineering.

Creating such sections of a general speech course is not new [8]. However, what distinguished this effort is that the section was designed and taught by faculty from the Department of Communications Arts and Sciences and the College of Engineering. The latter has degrees in engineering and works with the presentation-component courses of several engineering departments. With this team, the modified course was truly an interdisciplinary effort, interweaving the theoretical foundation of speech communication with examples, vocabulary, practical assignments, and nuances of the engineering discipline. In addition, the course aimed higher than most speech courses and engineering courses with presentation components to challenge the status quo of some aspects of engineering presentations - in particular, the use and design of visual aids. Moreover, although some Colleges of Engineering, such as the University of Wisconsin-Madison [9], have created effective speech courses within the College of Engineering, the engineering sections of our course go a step beyond that by fulfilling a general education requirement for our students.

To assess the effectiveness of the engineering section, this paper addresses the following research questions:

1. Did engineering students who completed an engineering section feel more confident in their ability to communicate effectively than engineering students who completed a regular section?

2. How did engineering students' self-perceptions compare to how speech instructors evaluated students' ability to communicate effectively?

3. Did the engineering communication sections affect women and underrepresented minority students differently from their male and majority counterparts?

First, we describe the engineering sections of the course, emphasizing what distinguishes the sections from the regular sections. Then we describe the methods for measuring the public speaking self-efficacy of the students. The paper concludes with the results and corresponding discussion.

\section{Differences between Engineering Sections and Regular Sections}

Three main differences existed between the engineering sections and the regular sections of the general education course. These differences occurred in the (1) choice of examples and terminology for the instruction, (2) the choice of topics for the major speeches, and (3) the expectations for delivery and visual aids. 


\section{Choice of Examples and Terminology in Instruction}

In the engineering sections, the instructor strove to incorporate engineering examples to anchor the communication principles taught. Two examples included model speeches given by the engineering faculty member on the effects of acid rain and on using dogs to detect explosives., Another example was a class analysis of the communications associated with the Space Shuttle Challenger disaster as an example for rhetorical analysis.

In the engineering sections, the instructor strove to either show connections between terms (such as "speech" and "presentation") or to select terms that are commonly used in engineering. For instance, the second assignment was named the "solution speech," as opposed to the "policy speech," which was the assignment name in the general sections. Moreover, the connection was made that the combination of the first assignment (the problem speech) and the solution speech formed the nucleus of a proposal, which is a type of presentation commonly given by engineers. In other words, this combination of speeches constitutes the Statement of Problem and Proposed Objectives of a typical proposal.

\section{Choice of Topics for the Major Speeches}

For three major speeches in the engineering sections, the students were free to select any technical issue. Here, the term technical was broadly defined to accommodate the different disciplines of engineers and the different levels (first year through fourth year) of the participating students. Ideally, students would take this course in their first or second year, and most students do, but Penn State is so large and has such a large number of transfer students in the third year, that some students are unable to take the course until they are juniors or seniors.

Topics for the problem and solution speeches included the following:

Loss of aircraft communications at the North Pole

Traffic in State College on football game days

What to do with waste tires

What to do about aquatic invasive species in ship ballast tanks

As revealed by the list above, the topics were often interdisciplinary. For instance, the traffic topic turned out to be a traditional civil engineering problem addressed by a computer simulation analysis. In general, the best topics were specific enough that the student could achieve depth. Also, an opportunity was soon realized that topics such as the aquatic invasive species in the ballast tanks of ships compelled students to think globally. For instance, the ballast of ships often provides a way for an invasive plant species from one region of the world (say the Great Lakes) to find its way to another part of the world, such as a Chinese port.

Topics for the process speeches included the following:

How to frame a custom house

How a steam locomotive works

How a roller coaster brakes

How to create caramel 
As with the topics for the sequence of the problem and solution speeches, the topics varied a great deal. Also, the students found interesting ways to incorporate a technical perspective. For instance, the chemical engineering student addressing the topic of creating caramel went into the chemical equations to show how the amount of heat and water spelled the difference between the chemical structure for caramel and the chemical structure for a praline.

\section{Expectations for Delivery and Visual Aids}

Two expectations that were noticeably different in the engineering sections, in comparison with the regular sections, were the expectations for delivery and visuals aids. While students in the regular sections typically use note cards, either placed on a podium or carried in hand, the students in the engineering sections were expected to move away from the podium for extended periods, engage the audience with eye contact, and think through the content as they spoke, referring to content on visual aids when appropriate. This style follows the generally accepted style of delivery for engineering presentations.

Nothing inherently wrong exists with using note cards. However, when notes are available, many less experienced speakers will refer to those notes too much, thereby losing eye contact with the audience. Moreover, in the engineering discipline, a recent survey of engineering executives [10] has revealed an expectation exists for most technical presentations that the speaker will speak from what he or she knows, as opposed to reading notes. When a technical speaker relies too much on notes, many in the audience will begin to doubt that speaker's credibility.

Granted, this engineering style of delivery often leads to speakers placing too much text on visual aids and then reading those visual aids. Anyone who has attended an ASEE conference will see that situation occur in a significant portion of the presented papers. Still, we felt that if students were to become effective speakers in engineering, then they had to attempt this delivery style without notes, at least for portions of their presentations (moreover, as discussed below, we stressed ridding projected slides of unessential words).

The second expectation that was noticeably different between the engineering sections and the regular sections was the expectation placed on visual aids. Because communicating engineering often involves presenting complicated designs and large amounts of data in a precise fashion, visual aids are important. At present, the most common type of visual aid in engineering presentations is the presentation slide. For that reason, the engineering sections spent considerably more time on the design of slides than the regular sections did.

Although most presentation slides in technical presentations follow the topic-subtopic defaults of PowerPoint [11], the design has received much harsh criticism [12-14]. For instance, the cognitive psychologist John Sweller has said the following [7]: "The use of the PowerPoint presentation has been a disaster. It should be ditched.....It is effective to speak to a diagram, because it presents information in a different form. But it is not effective to speak the same words that are written, because it is putting too much load on the mind and decreases your ability to understand what is being presented."

Given this criticism and given that the topic-subtopic design was not the product of research, but was simply chosen by the computer scientists who created PowerPoint [15], we 
asked our students to challenge PowerPoint's defaults. One alternative that we taught was the assertion-evidence design $[5,11,16]$, which has a much stronger theoretical and experimental foundation. This assertion-evidence slide design calls for a succinct sentence headline, no more than two lines, supported by visual evidence: photographs, drawings, diagrams, and graphs. If words and equations are incorporated, they are done so in a visual manner. Figure 1 presents a student slide that follows this design.

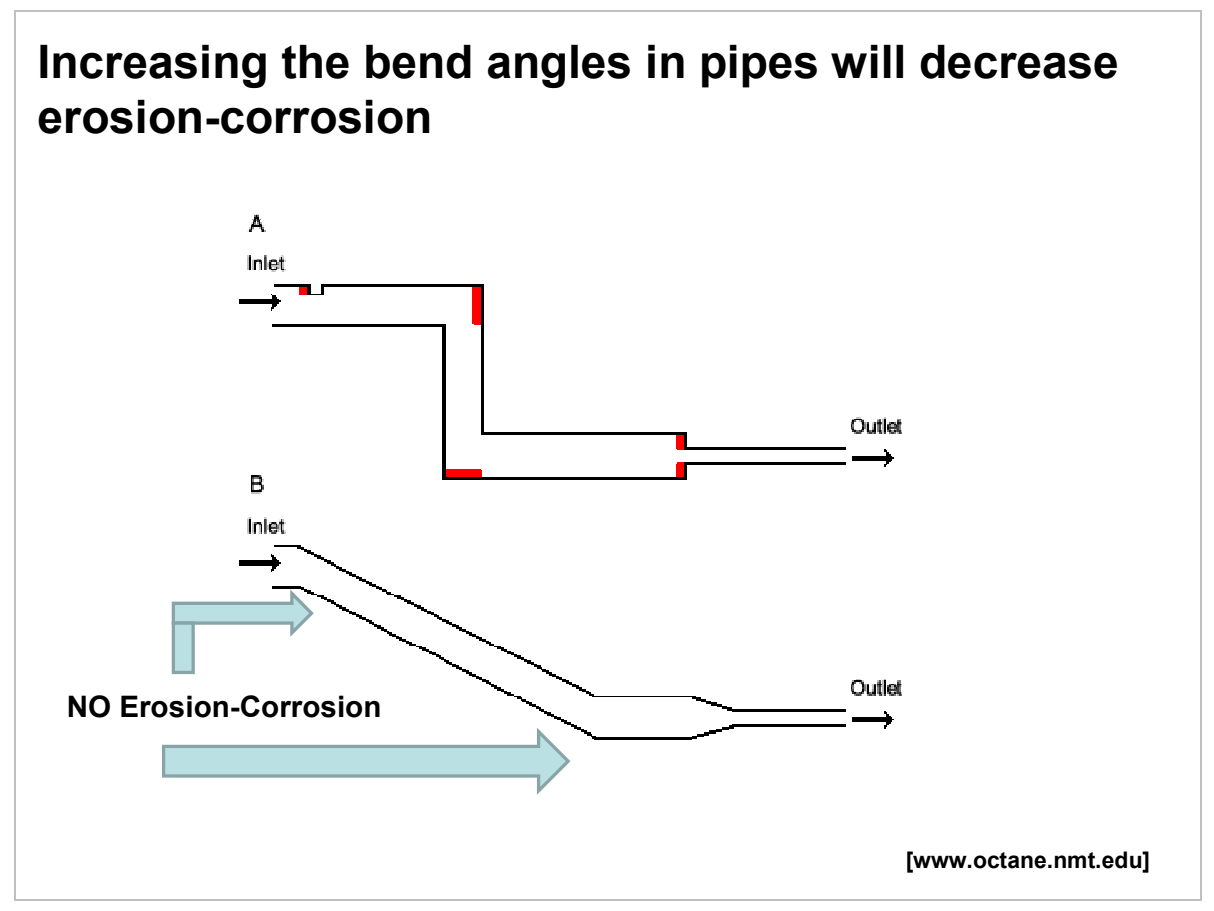

Figure 1. Sample slide from a student presentation [17]. This slide follows the assertionevidence design.

Several reasons exist for emphasizing the assertion-evidence design. One theoretical advantage of the assertion-evidence design is that the sentence-assertion headline more readily orients the audience during the presentation to the purpose of each slide than a single word or phrase headline does [4]. Another theoretical advantage is that having a sentence-assertion headline allows the presenter to clearly emphasize the most important assertion of the slide by giving that assertion more typographical emphasis than it would receive in a bullet list within the body of a traditional slide. This emphasis of the presentation's assertion is particularly important in persuasive presentations, because audiences are more likely to believe an argument if they know the assertions of the talk [18].

Still a third theoretical advantage is that the assertion-evidence (A-E) design more closely follows the principles of multimedia design [19] than the traditional design of PowerPoint does. One principle, which is termed the multimedia principle, is that audiences understand and retain more when words and relevant pictures are presented, rather than when words alone are presented. In the A-E structure, pictures are required in the form of photographs, drawings, graphs, equations, and words arranged visually. While the traditional structure certainly does not preclude pictures, pictures are not as easily accommodated. Moreover, in the traditional structure, the default option of a large block of bulleted text in the slide's body is what 
often ends up being chosen. A second principle of multimedia learning is that audiences demonstrate superior understanding and retention of information when extraneous information is removed from the presentation [20]. The requirement of the sentence-assertion headline in the assertion-evidence design compels presenters to have more focus in designing the slide's body. In particular, the presenter focuses on supporting that assertion rather than coming up with associated subtopics, which may very well be extraneous.

Recent experimental evidence reveals that using the A-E slide design, as opposed to the traditional design, leads to more comprehension and retention by audiences of the presentation material. For instance, placing key assertions in the sentence-assertion headlines of the A-E slides, as opposed to the body of a traditional slide, led to statistically significant increases ( $\mathrm{p}<$ $0.001)$ in the comprehension and retention of those assertions [21].

\section{Methods}

This section discusses the instrument we used to assess the public speaking self-efficacy of the participants. Our intent was to use the instrument to assess the three research questions listed in the Introduction. In addition, students in the engineering sections also wrote a reflective essay at the end of the semester that provided another source of data.

\section{Participants}

At the beginning of the fall 2007 semester, 773 students (out of 1788) completed the Public Speaking Self-Efficacy instrument (44\%) and gave their consent to use the data for this research study. At the end of the semester 287 of them completed the instrument again (37\%). Instructors completed the same instrument for 243 of these students (31\%). All instructors gave their consent to use the data for this research study. In the two engineering sections, $100 \%$ of the students completed the pre- and post-survey, and their instructor completed the instructor survey for each student.

Out of 773 students, 141 were engineering students (18\%). Out of these engineering students, 56 were in the engineering sections of the speech communication course, while 85 were in the regular sections. In addition, 75 engineering students completed both the pre- and postsurvey.

\section{Public Speaking Self-Efficacy Instrument}

The public speaking self-efficacy instrument consisted of ten items related to various aspects of public speaking, including delivering a well-organized presentation, developing effective visual aids, keeping expert and non-expert audiences engaged, and effectively answering questions. The items are listed in Table 1. The items measured public speaking selfefficacy reliably (Cronbach's alpha $=.90, \mathrm{~N}=773$ ). We administered the same instrument at the end of the semester; the items measured public speaking self-efficacy reliably again (Cronbach's alpha $=.89, \mathrm{~N}=279$ ). See Table 1 for the items. 
Table 1: Public Speaking Self-Efficacy Instrument

\begin{tabular}{l} 
When presenting in a class, I am ... [indicate level of confidence] confident that I can ${ }^{*}$ : \\
a) Make an effective presentation. \\
b) Develop a presentation with good content. \\
\hline c) Keep the audience engaged. \\
\hline d) Connect well to an audience that is familiar with the topic I present. \\
\hline e) Connect well to an audience that is not familiar with the topic I present. \\
\hline f) Deliver a well-organized presentation. \\
g) Design effective visual aids. \\
\hline h) Deliver effectively (eye contact, use of voice, movements, etc.). \\
\hline i) Give an effective summary of the information I presented. \\
g) Answer questions from the audience effectively.
\end{tabular}

* Students rated these items on a scale from "Not at all confident" (=1) to "Completely Confident" (=6)

We also asked students' instructors to evaluate the students on the same items. The question was worded as follows: "When presenting in a class, I am ... [indicate level of confidence] confident that the student can". The items measured Student Public Speaking Efficacy assessed by instructors reliably (Cronbach's alpha $=.97, N=241$ ).

Because the items showed high internal consistency for students both at the beginning and end of the semester and for instructors at the end of the semester, it is justified to take the average of all ten items to create a Public Speaking Self-Efficacy score for students, one measured at the beginning of the semester and one measured at the end of the semester, and one Public Speaking Student Efficacy score for instructors measured at the end of the semester. These average scores were used to answer the research questions.

\section{Results}

To answer the research questions, engineering students in the engineering sections have to be comparable with the students in the regular sections at the start of the semester. We compared engineering students in the engineering and regular sections on GPA and semester standing in a multivariate analysis of variance. In this comparison, we found a statistically significant difference $(F(2,137)=3.07, p=.05)$ that can be attributed to the difference in GPA. Students in the engineering sections $(M=3.1)$ had a significantly lower GPA than their counterparts $(M=3.3), F(1,139)=6.17, p=.01$.

Females and males were distributed equally in the engineering and regular sections of the speech communication course; $20 \%$ and $21 \%$ of the students were females in the engineering and regular sections respectively; $\chi^{2}(1,141)=.05, p=.83$. The number of students of underrepresented minorities was lower in the engineering sections ( 3 students) compared with the regular sections (13 students). Because of the low numbers in both sections, this difference only approached statistical significance $\left(\chi^{2}(1,141)=3.315, p=.07\right)$. 
Students in the engineering sections had a slightly lower public speaking self-efficacy score $(M=4.0)$ than engineering students in regular sections $(M=4.3)$; this difference approached statistical significance, $F(1,140)=3.05, p=.08$.

\section{Public Speaking Self-Efficacy in Engineering and Regular Sections}

The first research question asked whether engineering students who completed an engineering section of the speech communication course felt more confident in their ability to communicate effectively than engineering students who completed a regular section. To answer this question, we compared answers of the 75 engineering students who completed the Public Speaking Self-Efficacy instrument at the beginning and the end of the semester.

A T-Test showed that both groups increased their confidence at the end of the semester $(M=0.8, N=75, t=-10.24, p=.00)$. An analysis of variance showed that students in the engineering sections increased their public speaking self-efficacy slightly more than students in the regular sections; this difference approached statistical significance, $F(1,74)=3.73, p=.06$. See Table 2 for the means.

Overall, engineering students in the engineering sections started with slightly lower public speaking self-efficacy scores than engineering students in regular sections, but the students in the engineering sections caught up with their counterparts by the end of the semester.

Table 2: Public Speaking Self-Efficacy (SE) in Engineering and Regular Sections

\begin{tabular}{|r|c|c|}
\hline & \multicolumn{2}{|c|}{$\begin{array}{c}\text { Speech Communication Course } \\
\text { Section }\end{array}$} \\
\hline SE Score Start of Semester & Engineering & Regular \\
\hline Increase SE at End Compared to Start of Semester & 4.0 & 4.3 \\
\hline
\end{tabular}

In addition to an overall assessment, we analyzed the ten specific items that were listed back in Table 1. For most of the items, no statistically significant differences in the selfefficacies occurred. However, for the design of visual aids, engineering students in the engineering sections increased their self-efficacy more than engineering students in the regular sections; this difference was statistically significant $(p=.020)$. In addition, for the issue of delivery, engineering students in the engineering sections increased their self-efficacy slightly more than engineering students in the other sections; this difference approached statistical significance $(p=.054)$.

\section{Student and Instructor Evaluations of Student Public Speaking Efficacy}

The second research question asked how engineering students' self-perceptions compared to their instructors' evaluation of students' ability to communicate effectively. A T-test compared the average Student Public Speaking Self-Efficacy with the average Public Speaking Student Efficacy. The results showed no statistical difference between assessments by students and instructors, $(M=4.8), N=64, t=.15, p=.88$. This agreement indicates that students have a realistic perception of their oral communication abilities. 
To explore if there were any particular items on which students and instructors might disagree, we conducted an additional paired comparison T-Test in which we compared students' and instructors' answers on each of the ten individual items. We applied a Bonferroni correction to adjust for the increased probability of Type I errors resulting from multiple independent tests. We set the probability level to $5 \%(p=.05)$ for a single analysis; therefore, we tested at a significance level of $p=.005(.05 / 10)$ for the multiple analyses with the individual items. The results showed no statistical differences on any of the individual items. Therefore, we conclude that students have a realistic perception of their oral communication abilities in general and based on each individual topic related to oral communication.

\section{Effect of Engineering Sections on Gender and Ethnicity}

The third research question asked whether the engineering communication sections affected women and underrepresented minority students differently from their male and majority counterparts. Unfortunately, only four women engineers and three students from underrepresented minorities participated in the regular sections; only two minorities participated in the engineering sections. These numbers are too low to include gender and ethnicity in statistical analyses.

One interesting result that arose from the reflection essays in the engineering sections at the end of the semester was that of the 11 female students in the engineering sections, all 11 explicitly admitted the nervousness that they had at the beginning of this course for speaking in public. In contrast, fewer than half of the male students explicitly admitted having any nervousness. The issue of nervousness weighed much more on the female students. For instance, 10 of the 11 female students brought up the issue of nervousness in the first two paragraphs of the 2-page essay (for the males, the admission of nervousness generally occurred later in the essay).

Also, the degree of nervousness for the female students was high. For instance, in the second sentence of her essay, one female student wrote about how she felt at the beginning of the course: "I was terrified of public speaking and I was nervous to have to take an entire class on that." Another wrote the following: "In September, I was terrified of giving speeches in front of my peers. I so badly wanted to drop this class that I cried one night." Interestingly, the female students on average gave presentations that were at least as strong as, if not stronger, than the male students. In addition, the source of nervousness did not simply arise because the female students might have had less experience than the male students speaking in public. In fact, one of the female students had given the valedictory address of her high school to an audience of more than 2000 .

\section{Conclusions and Implications}

Overall, students in the engineering sections increased their public speaking self-efficacy slightly more than students in the regular sections; this difference approached statistical significance $(p=.06)$. Given that no statistical difference existed in the student and instructor 
evaluations of the student public speaking efficacy, we have much confidence in this result. Moreover, this result likely would have achieved statistical significance if we had larger sample sizes: 52 engineering students reported in the engineering sections, but only 23 engineering students reported from the regular sections. For further analysis, we intend to examine the responses from science students in the regular sections because scientific presentations and engineering presentations are so similar in terms of audience, purpose, and occasion.

One statistically significant increase in the public speaking self-efficacy did occur for the issue of visual aids $(p=.020)$. That result was not surprising because the engineering sections expected students to rise above the topic-subtopic defaults of PowerPoint and to use the assertion-evidence slide design as a starting point. The assertion-evidence design has a much stronger research foundation than the commonly followed topic-subtopic design propagated by PowerPoint's defaults.

Approaching a statistically significant increase was the issue of delivery $(p=.054)$, which follows because students in the engineering sections were encouraged to put down the note cards, to move away from the podium, and to engage the audience. This delivery style is in line with the culture of engineering presentations. Because engineering students are well aware of that culture through their classes, the engineering students in the engineering sections likely felt as if their own deliveries were becoming more effective as their deliveries fell more in line with what the expectations of engineering are.

Although the low number of female responses from the regular sections prevented us from answering the question about how the engineering sections affected female students, the reflective essays by the female students at the end of the semester did reveal an interesting finding: the pronounced nervousness at the beginning of the course that female students felt, in comparison with male students, about speaking in public. Granted, that finding could be skewed because male students, for cultural reasons, might have been reluctant to admit their nervousness in the essays. Nonetheless, the finding is making us more sensitive to the nervousness that female students might be feeling about their speaking assignments. In future engineering sections of the course, we are devoting more class time to discussing the subject of nervousness, incorporating more videos of female speakers in our instruction, and making sure that all students know our doors are open to discuss this issue at any time.

Because of the increases in the public speaking self-efficacy by the students in the engineering sections and the general enthusiasm shown by the engineering students for the engineering sections, the College of Engineering is doubling the number of sections in 20082009 to meet the anticipated demand. Future research will involve assessing the long-term effects of taking these special engineering sections. That assessment will occur through surveys of engineering students in their senior year. Another possible assessment is to have independent evaluators (such as engineering faculty members or co-op supervisors) assess the oral communication skills of senior engineering students and then to compare the results for those students who have taken the special engineering sections of the speech course with the results for those students who have taken the regular sections. 


\section{Bibliography}

1. Dorothy A. Winsor, Writing Like an Engineer (Mahwah, NJ: Lawrence Erlbaum Associates, 1996), pp. 2-3, 11.

2. Audeen W. Fentiman and John T. Demel, "Teaching Students to Document a Design Project and Present the Results," Journal of Engineering Education (October 1995), pp. 329-333.

3. Russ Pimmel, "Cooperative Learning Instructional Activities in a Capstone Design Course," Journal of Engineering Education (July 2001), pp. 413-421.

4. Richard E. Mayer, Multimedia Learning (New York, NY: Cambridge University Press, 2001).

5. Michael Alley, and Kathryn A. Neeley, "Rethinking the Design of Presentation Slides: A Case for Sentence Headlines and Visual Evidence," Technical Communication, vol. 52, no. 4 (2005), pp. 417-426.

6. John Sweller, "Implications of Cognitive Load Theory for Multimedia Learning," The Cambridge Handbook of Multimedia Learning, ed. by Richard A. Mayer (New York: Cambridge Press, 2005), pp. 19-30.

7. Patty, Anna (2007, April 4). Research points the finger at PowerPoint. The Sydney Morning Herald, http://www.smh.com.au/articles/2007/04/03/1175366240499.html.

8. J.L. Stephens and L. Marsicano, "Adapting the Basic Speech Course for Engineering and Engineering Technology Majors," Journal of Technical Writing and Communication, vol. 14 (1984), p. 140.

9. “EPD 275: Technical Presentations," http://www.engr.wisc.edu/epd/courses/epd275.html (Madison, WI: College of Engineering, University of Wisconsin, downloaded 17 January 2008).

10. Judith Norback, "Georgia Tech Workforce Communication Program: Students' Values and Self-Perceptions Regarding Capstone Design Workforce Presentation Instruction," session 3561 (Honolulu: ASEE National Conference, 2007).

11. Jean-luc Doumont, "The Cognitive Style of PowerPoint: Not All Slides Are Evil," Technical Communication, vol. 52, no. 1, pp. 64-70.

12. Edward Tufte, The Cognitive Style of PowerPoint (Cheshire, CT: Graphics Press, 2003).

13. Ian, Parker, "Absolute PowerPoint," The New Yorker (May 28 2001).

14. Anna Patty, "Research Points the Finger at PowerPoint," The Sydney Morning Herald, http://www.smh.com.au/articles/2007/04/03/1175366240499.html (April 4 2007).

15. Lee Gomes, "PowerPoint Turns 20, As Its Creators Ponder a Darlk Side to Success," Wall Street Journal, http://online.wsj.com/article/SB118228116940840904.html(20 June 2007), p. B-1.

16. Cliff Atkinson, Beyond Bullet Points: Using Microsoft PowerPoint to Create Presentations That Inform, Motivate, and Inspire (Redmond, WA: Microsoft Press, 2003).

17. Scott Burnett (2007, October 4). Presentation: Investigating erosion-corrosion in industrial pipelines. $C A S$ 100A: Effective Speech for Engineers. State College: The Pennsylvania State University.

18. Stephen E. Toulmin, The Uses of Argument (New York, NY: Cambridge University Press, 2003).

19. Richard E. Mayer, Multimedia Learning (New York, NY: Cambridge University Press, 2001).

20. Richard E. Mayer, "Principles for Reducing Extraneous Processing in Multimedia Learning: Coherence, Signaling, Redundancy, Spatial Contiguity, and Temporal Contiguity Principles," The Cambridge Handbook of Multimedia Learning (Cambridge: Cambridge Press, 2005), pp.183-200.

21. Michael Alley, Madeline Schreiber, Katrina Ramsdell, and John Muffo, "How the Design of Headlines in Presentation Slides Affects Audience Retention," Technical Communication, vol. 53, no. 2 (2006), pp. 225 234. 